\title{
Cross-National Proximity in Online Social Network and Protest Diffusion: An Event History Analysis of Arab Spring
}

\author{
K. Hazel Kwon \\ Walter Cronkite School of Journalism \\ Arizona State University \\ khkwon@asu.edu
}

\author{
Jeff Hemsley \\ School of Information Studies \\ Syracuse University \\ ijhemsle@syr.edu
}

\begin{abstract}
This study examines the role of online social network proximity in cross-national diffusion of offline protests. Drawn upon Valente's (1995) network diffusion model, the study operationalizes social network proximity-based protest exposure, using the international Facebook friendship share data. One year-long onsite protests during Arab Spring 2011 are examined using event history modeling. The findings offer evidence of an contemporaneous online network exposure effect on cross-national diffusion of protests. An expected lagged diffusion effect was not found, however. The paper presents an innovative approach to the scholarship of global protest diffusion and collective actions.
\end{abstract}

\section{Introduction}

The potential of online social networks for political mobilization has been widely discussed in the recent scholarship of collective action. Scholars highlight the virality of online social networks as a driving force behind the spontaneous emergence of offline collective actions [1,2]. Qualitative social science research anecdotally documents the importance of online information flows to facilitate offline actions [1-4]. Computational social scientists have primarily explored social media network's structural conditions for collective action mobilization under the assumption - either implicit or explicit - that online information flow should be a proxy for what is happening offline [5-8]. Despite scholarly interests in the role of online social networks in collective action diffusion, research that examines a causal effect of the exposure via social media on spatial diffusion offline is sparse.

The current paper aims to advance the understanding of the causal relationship between online communication flow and diffusion of protests across physical spaces, in particular countries. We highlight online social networks as a communication infrastructure that diffuses protest-oriented information amidst many other types of communicative activities. This study expands an event history modeling approach that previous quantitative social movement studies have taken, by additionally accounting for a social media exposure effect. Event history models of democratic change and social movements are designed to examine causality by including temporal dependence in the models.

The current project contributes to the advancement of the collective action research in digital age by (1) developing a computational measurement of protest exposure rates pertinent to online social network proximity; and (2) demonstrating the utility of this measurement on a cross-national diffusion context. As an exemplary case, we use the international Facebook friendship share data [9] and the 55 week-long onsite protest events collected from mainstream data journalism projects (i.e., Al-Jazeera and the Guardians).

\section{Literature}

\subsection{Diffusion Models of Collective Actions}

Diffusion theory explains a wide range of social phenomena involving the spread of beliefs, behaviors, norms, and products [10]. The realm of protest / collective actions is no exception. Diffusion research has converged onto major domains of collective action scholarship and substantiated the role of communication and social influence in spreading ideas and tactics $[11,12]$.

Three branches of diffusion studies of protest / collective actions have been developed: resource mobilization, framing, and communication structure [13]. While the first two branches are as important as the third topic, in this study we are focused only the third: communication structure. We do note, 
however, that avenues exist to extend out work into the other areas.

Collective action research focused on the communication structural aspects of diffusion, highlight the ways in which communication channels facilitate or restrain the spread of information and influence. This line of research emphasizes temporal processes and thus develops models that account for temporal autocorrelation.

Among various models, two models are noteworthy. First, Valente's [20] network diffusion model advances classical threshold models [18-19], by assuming that, as opposed to the population-wide average threshold level, each actor has a heterogeneous adoption threshold level pertinent to the actor's personal network context. The shift of focus from a population-average threshold, the underlying assumption of classical threshold models, to the personal network-oriented threshold is manifest in Valente's [15] operationalization of a personal network exposure rate, which is defined as the proportion of social contacts that have adopted a practice within an individual actor's personal network.

The second set of models, event history diffusion models, have been adopted to examine real-world social movement events [18-21]. An event history analysis technique is widely useful because it not only accounts for the temporal dependence among multiple events but also statistically tests the effects of diffusion variables on the likelihood of protest adoption. The event history framework has been used not only in social movement diffusion studies but also in international relation studies that test democracy dominos [26] and the spread of conflicts and warfare [27].

\subsection{Binary-Time-Series-Cross-Section Model}

Binary time-series-cross-section analysis (BTSCS) is a special type of event history analysis designed for datasets with a small sample of observational units $(<20)$, but larger temporal observations $(>20)$. This tends to be ideally for international relations data [27]. BTSCS begins with a likelihood ratio test to identify whether or not the model is influenced by temporal interdependence. If the test recognizes temporal dependence, the model then needs to be adjusted by treating the dataset as grouped duration data. [27]. A replication study [27] of international conflicts compared the differences between the original results (from the ordinary logit models) and the results from the logit models that correct for duration dependence. Their findings showed that the corrected model challenged some of the original results. That is, some originally significant variables were found to be non-significant [27].

\subsection{Spatial Diffusion and Media Proximity}

Some protest studies that use the event history modeling approach, examine a 'protest-withinspatial-boundary' as the observational unit instead of taking an individual protester as a unit of analysis. For example, studies [19, 24] on the Black solidarity movement and the spontaneous outbreaks of collective behaviors examined the spread of riots across different communities in the 1960s. Another study [18] examined the sit-in protests in 1960s by looking at the inter-city level of protest diffusion.

These studies consider 'a protest in city $i$ at time $t^{\prime}\left(P_{i t}\right)$ as an observation unit. This aggregate level of analysis is advantageous for highlighting the impact of communication proximity on spatial diffusion. For example, if city $A$ receives broadcast signals from city $\mathrm{B}$, or has a high rate of household subscription of newspapers produced in city B, then city A is proximate to city $\mathrm{B}$ in terms of mass media proximity. Literature on event history modeling [18, $19,24]$ has suggested that mass media proximity plays a significant role in the process of spatial protest diffusion. Furthermore, a qualitative study on the Southern textile worker strikes also demonstrated that the diffusion of strikes across states was indebted to the establishment of the radio network across Southern states in 1930s [25].

In addition to mass media proximity, physical distance has also been discussed as an important spatial diffusion variable. For example, a study used a threshold model to examine the temporal process of the establishment of trade unions in Sweden [22]. They showed a high level of contagion across physical acquaintance networks. Another study [30] on insurgency in the Paris Commune of 1871 also points out the role of residential area proximity in spreading the insurgency. The underlying assumption of physical distance effect is that the physically close areas will induce greater volume of human movements and social interactions that could facilitate information diffusion.

\subsection{Online Social Network Proximity as Diffusion Variable}

While both mass media proximity and physical distance are important communication channels for spatial diffusion of protest, online social networks should be considered a third communication infrastructure, distinctive from the mass media and physical proximity effects discussed above. We identify two reasons for this. 
First, online networks are multiplexed channels that blend mass media and interpersonal influence into a single flow of information [8]. This highly converged flow of information intermixes facts and opinions, and rationality and emotions, altogether expediting the contagion of collective identity and the spread of tactical knowledge [8]. Subsequently, the differentiation between mass media and interpersonal components in online social network environment have become analytically far more ambiguous, and so has the attempt to partition their effects from each other.

Second and more importantly, online social networks manifest a new notion of proximity: Online connections among the networked publics may generate a sense of cyber-neighborliness, both supplementary to offline interpersonal contacts at some times and idiosyncratic from offline social relationships at other times, contingent upon a communication context.

With respect to networks, proximity can be conceptualized as the strength of the path: the strength of connection between two actors in a network, often measured by the frequency of contact. Alternatively, the number of hops in the pathway between two actors can also represent proximity. That is, two actors who are not directly linked can still be linked by intermediaries. This is also referred to as closeness [27] or geodesic distance, which measures the shortest path, or number of intermediaries linking between two actors [28].

Sometimes, geographical proximity, also referred to as propinquity, is closely related with proximity in communication networks [29]. Geographical proximity has often been included in modeling collective actions on the premise that the nearby acquaintances should engage in more information exchanges than the distant others [18, 19]. However, information often flows along other paths other than the shortest [30, 37], and may also not flow across the strongest ties in networks [32]. Thus, the dimensions of proximity are much richer when it comes to explaining the mechanisms of information flow. In this sense, social network proximity is a distinctive notion from geographical proximity.

We highlight the exposure to information from the other sources as an essential parameter to define proximity $[32,33]$. Relational network structure is particularly important in estimating the magnitude of information exposure from "proximate" others because relational structures are the communication infrastructure through which shared attitudes and behaviors are developed. For example, studies have shown informal social proximity has a stronger effect on employees' job-related perceptions than geographical proximity and job-positional proximity $[32,33]$. While analogous to the social proximity defined within an organizational setting, "online social network proximity" may be distinctive from traditional interpersonal relational structures in that it is largely determined based on the link structure, which collapses both interpersonal (e.g., friends' online interactions) and impersonal (e.g. broadcasting, bot-generated messages) communication activities into a single channel.

\subsection{Summary}

To summarize, online social networks and the information exposure through them may define a new notion of proximity that may play an important role in contemporary collective action diffusion. This project explores the role of online social network proximity as a distinctive diffusion variable from the mass media proximity and physical proximity. Collective action diffusion studies (i.e., protests) based on event history analysis have examined geographical and mass media proximity effects by considering protest occurrence (at a place at a time) as a unit of analysis. This project intends to expand the spatial protest diffusion research by investigating online social network proximity effect as additional diffusion variable. In doing so, we borrow Valente's (1995) notion of personal network exposure.

\section{Research Hypotheses}

The main goal of this study is to explore the effect of online network proximity on cross-country protest diffusion. The study analyzes the longitudinal data of onsite protests during Arab Spring -a series of democratic movements that arose in the Middle East and North African (MENA) regions in 2010-2011. A broad range of scholarly work on the Arab Spring, most of which focuses on a single country context, discusses political opportunity processes [e.g., 4, 34]; resource mobilization [e.g., 3, 35] and collective action framing processes [e.g., 8, 36]. We do not discuss the details of extant Arab Spring research due to space limitations, but advise readers to refer to the author's previous paper for more information [37].

First, earlier protest diffusion studies underscore the role of mass media proximity in spatial diffusion of actions. Mass media has been known to be an important external communication channel that disseminates protest information across communities [10]. Research on Arab Spring has emphasized the role of Al-Jazeera, a widely penetrated transnational broadcasting network in Arab region, as an important 
alternative source of information to the state-run media in many countries in MENA [4, 36]. Accordingly, we hypothesize:

H1: The Al-Jazeera subscription rate will be positively associated with the focal country's likelihood of having a protest.

Next, we define online social network proximity based on the informal friendship connections among the countries on social media. One of the characteristics of digital era is that the information about another country is widely exchangeable via online social network. Subsequently, it is reasonable to speculate that the news about protests in a country during Arab Spring must have been shared via informal social media networks across the borders, subsequently influencing the spontaneous diffusion of protest ideas in other countries. That is, the informational exposure to other countries' protests via online social network may influence the likelihood of a protest occurrence in the focal country.

H2: The exposure to the protesting countries via online social network will be positively associated with the focal country's likelihood of having a protest.

Meanwhile, it may be possible that an online network exposure effect, if it exists, could be simply a byproduct of a propinquity effect because Arab Spring is a series of protests within MENA region. In order to investigate more rigorously the extent to which the online network proximity effect uniquely accounts for the diffusion process, rather than being a residue of the within-region propinquity effect, the study compares the effects between the regional propinquity and online social network proximity.

RQ1: Is there a difference between the withinregion propinquity effect and the social media network proximity effect in predicting the protest diffusion?

\section{Research Design}

\subsection{BTSCS}

Given the potential temporal interdependence of protest occurrences within each country, an event history analysis technique was applied. In particular, binary time-series-cross-section analysis (BTSCS) is a special case of event history techniques designed specifically for international relational data that often includes a small sample of observed units (i.e., country) with a large number of time points [23]. BTSCS specifies a discrete time hazards model with multiple events, derived from the Cox proportional hazards model:

$P\left(\left.y_{i, t=1}\right|^{\mathbf{x}_{i, t}}\right)=h\left(\left.t\right|^{\mathbf{x}_{i, t}}\right)=\frac{1}{1+e^{-\left(\mathbf{x}_{i, t} \beta+\kappa_{t-t 0}\right)}}$

where $y_{i, t}$ represents the binary information whether a protest occurs in country $i$ during the week

$t, \mathbf{X}_{i, t}$ represents the set of independent variables for the country $i$ at the week $t . \kappa_{t-t 0}$ is a temporal dummy variable denoting the length of the spell of non-eventful weeks (non-protesting weeks), from the preceding eventful week $t 0$ to the observing week $t$. Following the recommendation [23], we replaced the

set of $\kappa_{t-t 0}$ dummy variables with a smooth function of $t-t 0$ by spline interpolation.

\subsection{Variables}

4.2.1. Offline protest data. The Guardian and AlJazeera provided detailed coverage of the timeline of Arab Spring. Their data were referenced to generate the longitudinal protest data of 16 countries in MENA: Algeria, Bahrain, Egypt, Iran, Iraq, Jordan, Kuwait, Lebanon, Libya, Morocco, Qatar, Saudi Arabia, Syria, Tunisia, UAE, and Yemen. Iranian data was included despite different language culture (Persian as opposed to Arabic) given that "the wave of democratization reached countries with sizeable Shia communities" [38]. Iran's majority population is Shia. Israel and Palestine were not put into the analysis because the majority of protests in those areas were irrelevant to the democratic movement affecting the larger region. The two countries have been in the long-lasting conflict and some of protests in these countries during the Arab Spring period were not consistent with the democratic ideologies that other protests promoted.

To enhance the representativeness of protests, a protest occurrence was included in the analysis only when both newspapers covered the incident. Also, given that our interest is on the occurrence of protest rather than the continuation or intensity, we aggregated protest events onto a weekly basis, and transformed it into a binary, 55 weeks of time points spanning from December 19, 2010 to December 17, 2011. We adopted this binary transformation of protest data across weeks from previous event history protest research [18-19]. 
4.2.2. Within-Region Propinquity (WRP) Effect. The exposure to protests of all countries in MENA, except the protests in a focal country $i$, was measured by simply counting the number of protesting countries in each week. This variable assumes that an occurrence of protest in a country within the region is equally impactful to the focal country regardless of the availability of other communication channels.

4.2.3. Online Network Exposure (ONE) Effect. Publicly available, international Facebook friendship share data [9,39] was used as a proxy for social media proximity among each pair of countries as of 2011. The data is a ranking based on the volume of Facebook friendships between two countries, divided by the total number of Facebook friendships within those countries. [39]. For example, the top five countries with highest social media proximity to Egypt were Saudi Arabia (rank 1), Jordan (rank 2), Tunisia (rank 3), Palestine (rank 4) and UAE (rank 5). These ranks were inversely coded so that the top ranked country is weighted by 5 , top second country weighed by 4 , and so on. Non-ranked countries were coded with zero to indicate no connections, or no social network proximity. Based on this logic, the social network proximity matrix $\mathbf{W}_{i j}$ among MENA countries was constructed.

Based on the social network proximity matrix $\mathbf{W}_{i j}$, a variable called "online network exposure" rate (ONE) was generated. Specifically, ONE is operationalized by adopting Valente's notion of personal network exposure. Personal network exposure is the proportion of the adopters within a focal actor's local (or personal) network. Recently, Author [40] borrowed the concept of personal network exposure to experiment with social influence mechanisms in mobilizing advocacy efforts on Facebook. In the current study, each country is treated as a focal actor, and the local network is the social network proximity $\mathbf{W}_{i j}$. Also, adoption in the context of this study refers to protest occurrence. ONE is then computed from multiplying $\mathbf{W}_{i}$ by the weekly protest occurrence matrix such that

$$
\boldsymbol{E}_{i t}=\frac{\sum \boldsymbol{W}_{i j} \boldsymbol{Y}_{j t}}{\sum \boldsymbol{W}_{i}}
$$

where $\boldsymbol{E}_{i t}$ represents ONE of a country $i$ during a week $t, \mathbf{Y}_{j t}$ is the adoption matrix which represents whether or not a protest occurred in a country $j$ for during week $t, \mathbf{W}_{i j}$ is the network matrix, which represents the weighed (ranked) friendship share by a country $j$ with a country $i$. $\mathbf{W}_{i}$ is the row vector that represents a country $i$ 's total friendship shares originating from all MENA countries.
The variable ONE underscores that not all protesting countries exert equal influence on the focal country. Instead, the impact of the protest event in a country is disproportionately significant contingent on the size of Facebook friendship share with the focal country.

4.2.4. Mass Media Proximity. Al-Jazeera is known to play a key role in diffusing Arab Spring. AlJazeera channel subscription rate in each country was retrieved from the marketing company website Allied-Media [41]. The total number of subscribers was calculated as a function of the channel penetration rate and the Muslim composition of adult population in each country, considering $96 \%$ of AlJazeera subscribers being Muslim. Note that this variable only considered the channel subscription rate. The exposure to Al-Jazeera news via social media channels were not taken into account.

4.2.5. Control variables. (1) As an indicator of economic status, GDP per capita of each country was retrieved from the World Bank website (2010). (2) The number of dictatorship years in each country was collected from the data documented by [34].

\section{Results}

\subsection{Descriptive Analyses}

We examined a total of 55 weeks of protests in 16 countries in MENA. At least one protest has occurred in any one of the countries for a total of 53 weeks during Arab Spring. A country was exposed to an average of 2.61 protesting countries a week (WRP). The average ONE was 0.144. On Average, GDP per capita for a country was 14,969 (in USD), the average length of dictatorship was 14 years, and the Al-Jazeera subscribing population in a country was 2.83 million. Bivariate correlations showed that the number of protests were correlated with GDP per capita and the length of dictatorship. The correlation between WRP and ONE was fairly high $(r=.46)$. Note, however, the correlations did not take account for the temporal dependence.

Table 1. Descriptive analyses: Means, standard deviations, and correlations

\begin{tabular}{|c|c|c|c|c|c|c|}
\hline & 1 & 2 & 3 & 4 & 5 & 6 \\
\hline Prot & & & & & & \\
\hline GDP & -.20 & & & & & \\
\hline DIC & .30 & -.14 & & & & \\
\hline
\end{tabular}




\begin{tabular}{|c|c|c|c|c|c|c|}
\hline Al-Ja & .03 & $-.47^{\prime \prime \prime}$ & $\begin{array}{l}-02 \\
\end{array}$ & & & \\
\hline WRP & -.03 & .06 & -.08 & -.01 & & \\
\hline ONE & .04 & $-.12^{(x)}$ & .00 & $.10^{* \pi}$ & .46 & \\
\hline $\bar{M}$ & .174 & $15 \mathrm{~K}$ & 14.00 & $28 \mathrm{~K}$ & 2.61 & 0.14 \\
\hline SDS & .379 & $18 \mathrm{~K}$ & 10.25 & $24 \mathrm{~K}$ & 1.40 & 0.20 \\
\hline \multicolumn{7}{|c|}{$\begin{array}{l}\text { Note: } \text { Prot }=\text { protest; GDP }=\text { GDP per capita } ; \mathrm{DIC}= \\
\text { dictatorship years } ; \mathrm{Al}-\mathrm{Ja}=\mathrm{Al}-\mathrm{Jazeera} \text { subscription } \\
\text { WRP }=\text { within-region propinquity exposure; } \mathrm{ONE}= \\
\text { online proximity exposure rate } ;{ }^{\star \star \star} p<.001 ;{ }^{\star \star} p<.01 ; \\
{ }^{*} p<.05\end{array}$} \\
\hline
\end{tabular}

Graphical representations of protest occurrences are presented in Figure 1. Figure 1A (top) is based on the total counts of protests, while Figure 1B (bottom) represents the same data after the binary transformation. We choose to use the binary data as a criterion variable for further analysis because the aim of the current paper is to demonstrate the evidence of cross-border diffusion, rather than to compare the intensity of protests within each country. While two countries, Qatar and United Arab Emirate (UAE), did not experience a protest at all, all other countries had at least one protest during the timeframe we studied. While Tunisia was known to be the earliest protesting country that successfully ousted their authoritarian leader, long-lasting protests were observed in other countries such as Bahrain, Egypt, Iran, Libya, Syria, and Yemen. Algeria and Lebanon were early protest adopters but the protests in these countries did not last long. In contrast, Libya, Syria, Yemen, and Iran, who joined the wave a few days later, showed longer durations of protests.

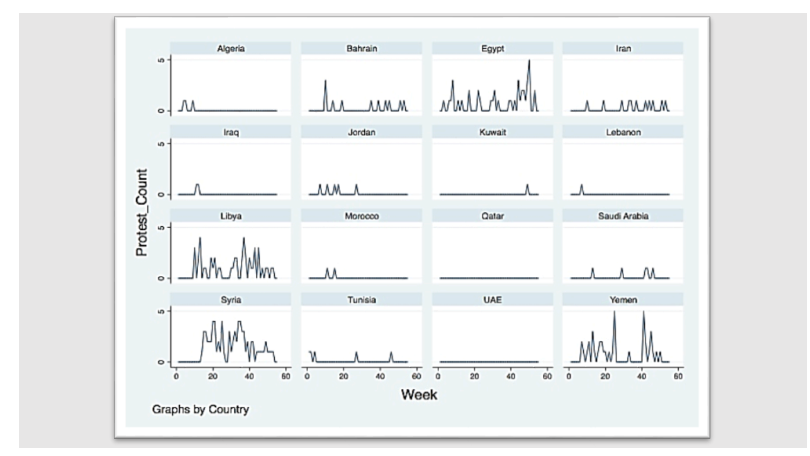

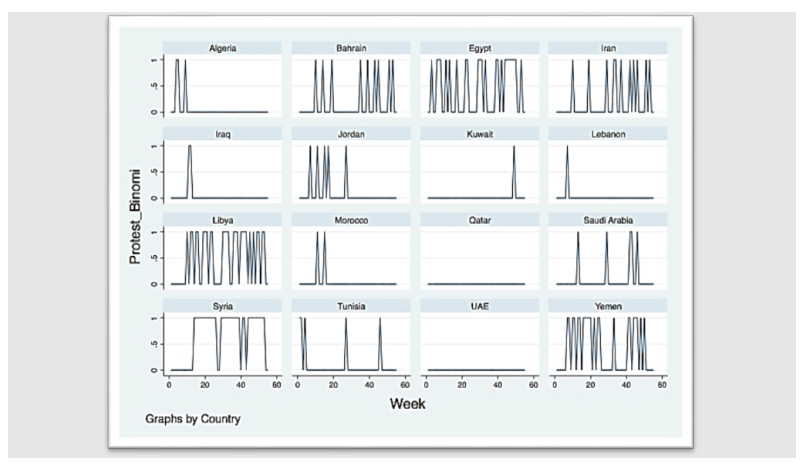

\section{Figure 1. Cross-national comparison of protests during Arab Spring: 1A (top) is based on the weekly protest counts. 1B (bottom) is based on the binary information whether a protest occurred on a given week.}

\subsection{BTSCS Analyses}

In order to examine whether temporal dependence exists in the data, a likelihood-ratio test was conducted to compare a baseline random-effect logit model with a grouped duration logit model. In the former we included control variables for GDP per capita, dictatorship duration, and Al-Jazeera subscription. In the later model we added event history specifications -i.e., the length of nonprotesting weeks since the previous protest and the time splines -to the baseline model. The likelihoodratio test confirmed the existence of a temporal dependence effect, $\chi^{2}=22.43, p<.001$. Therefore, the rest of modeling was built on the grouped duration logit model that accounted for temporal dependence.

When the spatial diffusion variables -WRP and ONE -were added together into the model, neither was significant, possibly due to the large shared variance between the two variables. However, when each was put into a separate model, the outcome suggested different results regarding the association of WRP and ONE with the protest occurrence.

Following recommendations from [23], we accounted for a potential contaminating effect of prior protests on later protests within a country in our models. In other words, a variable indicating the number of previous protests until $t-1$ was added to the group duration logit models. While the addition of this variable did not diminish the significance of the ONE effect, $\beta=1.12, p<.05$, or of the GDP per capita effect, $\beta=-0.000049, p<.05$, the effect of dictatorship lengths was no longer significant, $\beta=$ $0.03, p=.053$. 
We interpret the results by noting that a one unit of change in ONE, the likelihood of protest in a country at time $t$ increased 3.05 times. For a 1-dollar increase in GDP per capita, the likelihood of protest in a country at time $t$ decreased 0.001 times. This odds ratio for GDP per capita seems extremely small, but nonetheless could be a nontrivial predictor because the unit of analysis of GDP per capita was on a dollar-basis (Table 2). Interestingly, modeling with WRP showed no propinquity effect. We conducted a series of additional modeling with the lagged diffusion variables, i.e., WRP at $t-1$ and ONE at $t-1$. However, neither of the lagged variables significantly predicted the likelihood of protest.

Meanwhile, the duration of non-eventful (nonprotesting) weeks within a country -or "spells" in event history terminology -was significant and negatively associated with the likelihood of protest, $\beta$ $=-.51, p<.05$. The number of previous protests within a country was also a significant predictor of the protest, $\beta=.04, p<.01$.

Table 2. Within-Regional PropinquityBased Exposure Effect on Protest Diffusion

\begin{tabular}{|c|c|c|c|}
\hline & Coef. & Std. Err. & $\begin{array}{l}\text { Odds } \\
\text { Ratio }\end{array}$ \\
\hline GDP * & -0.00005 & 0.00002 & 0.99995 \\
\hline DIC * & 0.03986 & 0.01952 & 1.04066 \\
\hline Al-J & -0.00005 & 0.00010 & 0.99995 \\
\hline WRP & 0.12698 & 0.08047 & 1.13539 \\
\hline $\begin{array}{l}\text { Prev } \\
\text { protest * }\end{array}$ & 0.03709 & 0.01700 & 1.03778 \\
\hline $\begin{array}{l}\text { Nonprotest } \\
\text { _week * }\end{array}$ & -0.49990 & 0.20731 & 0.60659 \\
\hline spline1 & -0.05068 & 0.02715 & 0.95058 \\
\hline spline2 & 0.01182 & 0.00650 & 1.01189 \\
\hline spline3 & -0.00063 & 0.00046 & 0.99937 \\
\hline
\end{tabular}

Note: Log likelihood $=-295.231$, Likelihood ratio $x^{2}(9)$ $=44.22, p<.001 ;{ }^{*} p<.05 ; \mathrm{DIC}=$ dictatorship years; Al-J = Al-Jazeera subscription; WRP =Withi Region Propinquity; Prev_protest $=$ number previous protest in a country at t-1; Non-protest_week = duration of non-protesting weeks in a country

Table 3. Social Media Proximity-Based Exposure Effect on Protest Diffusion

\begin{tabular}{|l|l|l|l|}
\hline & \multicolumn{1}{|c|}{ Coef. } & Std. Err. & \multicolumn{1}{l|}{$\begin{array}{l}\text { Odds } \\
\text { Ratio }\end{array}$} \\
\hline GDP * & $\mathbf{- 0 . 0 0 0 0 5}$ & $\mathbf{0 . 0 0 0 0 2}$ & $\mathbf{0 . 9 9 9 9 5}$ \\
\hline DIC & 0.03866 & 0.02002 & 1.03941 \\
\hline
\end{tabular}

\begin{tabular}{|l|r|r|r|}
\hline Al-J & -0.00007 & 0.00010 & 0.99993 \\
\hline ONE * & $\mathbf{1 . 1 1 5 0 8}$ & $\mathbf{0 . 5 3 8 5 2}$ & $\mathbf{3 . 0 4 9 8 0}$ \\
\hline $\begin{array}{l}\text { Prev__ } \\
\text { protest * }\end{array}$ & $\mathbf{0 . 0 3 9 3 7}$ & $\mathbf{0 . 0 1 6 8 7}$ & $\mathbf{1 . 0 4 0 1 6}$ \\
\hline $\begin{array}{l}\text { Nonprotest } \\
\text { week * }\end{array}$ & $\mathbf{- 0 . 5 1 3 3 6}$ & $\mathbf{0 . 2 0 7 8 7}$ & $\mathbf{0 . 5 9 8 4 8}$ \\
\hline spline1 & -0.05271 & 0.02725 & 0.94866 \\
\hline spline2 & 0.01225 & 0.00653 & 1.01232 \\
\hline spline3 & -0.00063 & 0.00047 & 0.99937 \\
\hline
\end{tabular}

Note: Log likelihood $=-295.231$, Likelihood ratio $X^{2}(9)$ $=44.22, p<.001 ;{ }^{*} p<.05 ; \mathrm{DIC}=$ dictatorship years; $\mathrm{Al}-\mathrm{J}=\mathrm{Al}-\mathrm{Jazeera}$ subscription; ONE =online network exposure; Prev_protest = number previous protest in a country at $\mathrm{t}-1$; Non-protest week = duration of nonprotesting weeks in a country

Combining with the result from the ONE modeling with the temporal dependence results suggests that social media proximity-based diffusion may last only for a short term, likely within the same weekly window. Once the exposure to other countries has triggered a protest in the focal country, the subsequent protests heavily depend on the development of protests within the country. Meanwhile, Al-Jazeera subscription showed no association with the likelihood of protest. Table 2 and 3 present the results from modeling WRP and ONE effects along with other control variables.

\section{Conclusion and Discussions}

This study examined cross-national diffusion of protest. Like other diffusion phenomena, protest diffusion assumes the exposure to others' protest events. This study claims that cross-national diffusion of protest should be partly driven by the exposure to protests in cyber-neighboring countries, in addition to other important sociopolitical factors and temporal dependence. Adopting Valente's network diffusion model [20], we defined online network exposure $(O N E)$ as the exposure to other countries' protests, weighted by social media proximity, which we operationalize based on cross-national Facebook friendship sharing. The results suggest that ONE effect should be understood as distinct from a withinregion propinquity (WRP) effect that treated every country in the MENA region as having an equal impact on the protest occurrence in a focal country.

Although WRP was not significant, ONE was a significant and positive predictor of the probability of protest event. The effect of ONE remained significant even after accounting for the history of prior protests within a country as well as other temporal 
specifications. However, the ONE effect seems to be rather contemporaneous in that we failed to find a delayed effect: The one-week lagged ONE $(t-1)$ did not significantly predict the posterior protest on the following week $t$.

Our findings contribute to current protest diffusion scholarship in a few ways. First, the results quantitatively buttress the long-standing argument that social movements are contagious crossnationally. Many scholars have discussed different cases of cross-national diffusion for social movement ideologies and tactics. However, few have engaged in quantitative examinations of the diffusion process. By using event history modeling, the current study statistically confirms cross-national diffusion via social media proximity. The event history modeling approach is in line with the past protest diffusion studies that examined inter-city, or inter-community diffusion of collective actions [18, 19]. This study expands the evidence of spatial protest diffusion to a global scope.

Second, the fact that cross-national diffusion was found to be related to online social networks rather than through exposure to all other countries within the same geographic region (WRP) reaffirms the important role of online networks in the contemporary process of mobilization. The majority of previous research on social media and Arab Spring focuses on individual activists' use of social media toolkits. This study is a new attempt to understand Facebook friendship-based social media proximity as an "information infrastructure" [34, p.47] that supports all kinds of communicative activities, in the midst of which protest-related news, expressions, and stories may flow as a part.

While the ONE effect demonstrates the role of social media as a cross-border communication infrastructure, it does not pinpoint the flow of movement-specific information. Moreover, we did not consider Facebook connections with diasporic communities outside MENA region when computing social media proximity. For example, France had a large friendship share in Tunisia and Morocco, but was not included in the analysis. Likewise, the subcultural components like religious affiliations or ethno-linguistic relations, were not considered in defining social media proximity and ONE.

The unspecified information flow and omission of the larger global and cultural contexts are potential limitations of this study. For a more insightful understanding of social media proximity effects in the context of global protests or collective action diffusion, we recommend future research examine other forms of social media data that capture protestspecific message exchanges, for example on Twitter.
Third, our findings are consistent with the existing literature concerned with the international spillover of democracy. As democratic domino theory [26] suggests, one country's change is not isolated within that country. Instead, the country's change exerts normative and informational influence on other countries. International relational scholars have explored the diffusion of democracy from a geo-political and institution-centric perspective, which considers proximity effects of diffusion to be an emulation process among geographically nearby governments [24]. Our study complements the existing understanding of democratic dominos by offering evidence of social media proximity and its impact on cross-national spread of spontaneous, noninstitutional democratic changes. That is, this study underscores the importance of online social networks as a new mode of proximity that helps understand the relationships across global civil societies.

The current study has some limitations. One of the most urgent tasks to improve the quality of this project is to replicate the analysis with daily protest data. The spatial diffusion through ONE was found to be contemporaneous rather than to have a lagged effect. This result affords different interpretation. On the one hand, ONE has only a short-term effect on the protest diffusion process, lasting for less than a week. On the other hand, ONE effect could be a product of similarity in communication flows among the countries, which could have led to similar protest behaviors. If the latter proposition is correct, ONE should then be treated as a homophily variable as opposed to a diffusion variable. The examination of daily protest data with multiple lagged variables may help clarify the underlying mechanism of ONE effect.

Second, it is worthwhile to delve into why the number of Al-Jazeera subscriptions was not significant in this study. If Al-Jazeera was an important broadcasting network in spreading the protest ideas, the result should have produced a significant association with the protest occurrence, which was not the case in this study. One possible explanation could be that the simple subscription size is not a sufficient operationalization of the Al-Jazeera effect. The channel's news content could have been spread via Youtube, Twitter, Facebook, and other forms of social media outlets. If the exposure to this news channel via social media were taken into account, the result could have been quite different. Also, the subscription did not indicate the rate of exposure to protest-specific information via AlJazeera. Similar to the social media proximity, the unspecific nature of the Al-Jazeera penetration could limit the findings. 
Third, the notion of social media proximity is flexible depending on which online platform is concerned. For example, the hyperlink structure of the whole web sphere, Twitter mentioning relations, or YouTube video flows may not necessarily be similar to the proximity structure represented by Facebook friendship shares. Comparing among different representations of social media proximity and the subsequent metrics of ONE should be an interesting area that future research.

On a final note, this study only focused on the Arab Spring within MENA region. It will be worth exploring the diffusion of collective actions that involves a wider range of global participation beyond a single geo-political region. Within-region propinquity and social media proximity may be differently defined depending on the scale of diffusion boundary. The recent progress of data journalism projects that produce quantified archives of global events, and the availability of various social media data are promising for the advancement of scholarship of protest/collective action diffusion.

\section{Acknowledgements}

We would like to thank Sahar Ghanipoor Machiani (San Diego State University) and Clay Fink (Johns Hopkins University), as well as anonymous reviewers for providing helpful comments.

\section{References}

[1] W.L. Bennett, and A. Segerberg, "The logic of connective action", Information. Communication, and Society, 15(5), 2012, pp. 739-768.

[2] Castells M., Network of Outrage and Hope: Social Movement in the Internet Age. Cambridge: Polity Press. 2013.

[3] N. Eltantawy and J.B. Wiest, "Social media in the Egyptian Revolution: Reconsidering resource mobilization theory", International Journal of Communication, 5, 2012, pp. 1207-1224.

[4] M. Lim, "Clicks, cabs, and coffee houses: Social media and oppositional movements in Egypt, 2004-2011", Journal of Communication, 62(2), 2012, pp. 231-248.

[5] A. Bruns, T. Highfield, and J. Burgess, "The Arab Spring and Social Media Audiences English and Arabic Twitter Users and Their Networks", American Behavioral Scientist, 57(7), 2013, pp. 871-898.

[6] S. González-Bailón, J. Borge-Holthoefer, and Y. Moreno, "Broadcasters and hidden influentials in online protest diffusion", American Behavioral Scientist, 57(7), 2013, pp. 943-965
[7] G. Lotan, E. Graeff, M. Ananny, D. Gaffney, and I. Pearce, "The Arab Spring, the revolutions were tweeted: Information flows during the 2011 Tunisian and Egyptian revolutions", International Journal of Communication, 5, 2011, Article 31.

[8] Z. Papacharissi, and M. De Fatima Oliveira, "Affective news and networked publics: The rhythms of news storytelling on \#Egypt", Journal of Communication, 62, 2012, pp. 255-282.

[9] G.A. Barnett and G.A. Benefield, "Predicting international Facebook ties through cultural homophily and other factors," New Media \& Society, 2015, Online before print: doi: $10.1177 / 1461444815604421$

[10] Rogers, E. M. Diffusion of Innovations. New York: Simon and Schuster. 1995.

[11] McAdam, D., McCarthy, J. D., and Zald, M. N. Comparative Perspectives on Social Movements: Political Opportunities, Mobilizing Structures, and Cultural Framings. Cambridge: Cambridge University Press. 1996.

[12] R.K. Garrett, "Protest in an information society: A review of literature on social movements and new ICTs", Information Communication and Society, 9(2), 2006, pp. 202.

[13] D. Strang and S.A. Soule, "Diffusion in organizations and social movements: From hybrid corn to poison pills", Annual Review of Sociology, 24, 1998, pp. 265-290.

[16] M. Granovetter. "Threshold models of collective behavior", American Journal of Sociology, 83, 1978, 14201443.

[17] P. Hedström, "Contagious collectivities: On the spatial diffusion of Swedish trade unions, 1890-1940", American Journal of Sociology, 99, 1994, 1157-1179

[15] T.W. Valente, Network models of the diffusion of innovations (Vol. 2, No. 2). Cresskill, NJ: Hampton Press. 1995.

[18] K.T. Andrews and M. Biggs, "The dynamics of protest diffusion: Movement organizations, social networks, and news media in the 1960 sit-ins", American Sociological Review, 71(5), 2006, 752-777.

[19] D.J. Myers, "The diffusion of collective violence: Infectiousness, susceptibility, and mass media networks1", American Journal of Sociology, 106(1), 2000, 173-208

[20] D. Strang, "Adding social structure to diffusion model: An event history framework", Sociological Methods \& Research, 19(3), 1991, 324-353. 
[21] D. Strang and S.A. Soule, Diffusion in organizations and social movements: From hybrid corn to poison pills", Annual Review of Sociology, 24, 1998, 265-290.

[22] D. Brinks and M. Coppedge, "Diffusion is no illusion: Neighbor emulation in the third wave of democracy", Comparative Political Studies, 39(4), 2006, 463-489.

[23] N. Beck, J.N. Katz, and R. Tucker, "Taking time seriously: Time-series-cross-section analysis with a binary dependent variable", American Journal of Political Science, 42(4), 1998, 1260-1288.

[24] S. Spilerman, "Structural characteristics of cities and the severity of racial disorders", American Sociological Review, 41, 1978, 771-793.

[25] V.J. Roscigno and W. F. Danaher, “ Media and mobilization: The case of radio and southern textile worker insurgency, 1929 to 1934", American Sociological Review, 66, 2001, 21-48.

[26] R.V. Gould, "Multiple networks and mobilization in the Paris Commune, 1871", American Sociological Review, 56, 1991, 716-729.

[27] S.P. Borgatti, "Centrality and network flow", Social Networks, 27(1), 2005, 55-71.

[28] S. Wasserman and K. Faust, Social network analysis: Methods and applications. Cambridge Univ Press. 2004.

[29] D.C. Barnlund and C. Harland, "Propinquity and prestige asdeterminants of communication networks", Sociometry, 26, 1969, 467-479.

[30] G. Kossinets, J. Kleinberg, and D. Watts, "The structure of information pathways in a social communication network", In 14th ACM SIGKDD international conference on Knowledge discovery and data mining (pp. 435-443). 2008. ACM

[31] R.S. Burt, "The network structure of social capital. Research in Organizational Behavior”, 22, 2000, 345-423.

[32] R.E. Rice and C. Aydin, "Attitudes toward new organizational technology: Network proximity as a mechanism for social information processing", Administrative Science Quarterly, 36, 1991, 219-244.

[33] H. Ibarra and S.B. Andrews, "Power, social influence, and sense making: Effects of network centrality and proximity on employee perceptions", Administrative Science Quarterly, 38, 1993, 277-303.

[34] P.N. Howard and M.M. Hussain, Democracy's Fourth Wave? Digital Media and the Arab Spring. New York: Oxford University Press. 2013.

[35] Z. Tufekci and C. Wilson, "Social media and the decision to participate in political protest: Observations from Tahrir Square", Journal of Communication, 62(2), 2012, 363-379.

[36] N. Hamdy and E. H. Gomaa, "Framing the Egyptian uprising in Arabic language newspapers and social media", Journal of Communication, 62(2), 2012, 195-211.

[37] K.H. Kwon, W.W. Xu, H. Wang, \& J. Chon, "Spatiotemporal diffusion modeling of global mobilization in social media: The case of Egyptian revolution 2011", International Journal of Communication, 10, 2016, 73-97.

[38] E. Karagiannis, "The rise of Iran as a regional power: Shia empowerment and its limits", NATO Review Megazine, 2016. Retrieved from http://www.nato.int/docu/review/2016/Also-in-2016/irantehran-islamic/EN/index.htm

[39] M. Newman, "Interactive: Mapping the world's friendships", Facebook Stories, 2012. Retrieved from www.facebookstories.com/stories/1574/\#color=continent\& story $=1 \&$ country $=\mathrm{US}$

[40] K.H. Kwon, M.A. Stefanone, G.A. Barnett, "Social network influence on online behavioral choices: Exploring group formation on Social Network Sites", American Behavioral Scientists, 58(10), 2014, 1345-1360.

[41] Allied Media, "Al-Jazeera TV viewer demographics". Retrieved from http://www.alliedmedia.com/aljazeera/ 